\title{
Cytotoxicity of propolis nanopreparations in cancer cell monolayers: multimode of action including apoptotsis and nitric oxide production
}

\author{
Mahmoud S. Sherif ${ }^{1,2}$, Taha A. Rehab ${ }^{3}$, Zayed A. Hamdia ${ }^{3}$ and Vladmir P. Torchilin ${ }^{2}$ \\ ${ }^{1}$ Biophysics and Laser Science Unit, Research Institute of Ophthalmology, Giza, Egypt \\ ${ }^{2}$ Center for Pharmaceutical Biotechnology and Nanomedicine, Department of Pharmaceutical Sciences, School of Pharmacy, \\ Northeastern University, Boston, USA \\ ${ }^{3}$ College of Women for Arts, Science and Education, Ain Shams University, Cairo, Egypt
}

\begin{abstract}
Natural products are invaluable resource of anticancer drug discovery. They generally viewed as safe but weak, within the framework of nanotechnology, they can serve as template for potent anticancer drugs. We first evaluated the cytotoxic activity of different propolis extracts (water, 70\% ethanol, absolute ethanol and hexane) in many cancer cell lines, then the solid nanoparticles from the organic solvent extracts were prepared and their cytotoxicity was evaluated as well. Finally, 1,2-dipalmitoyl-sn-glycero-3-phosphocholine (DPPC) and 1,2-dioleoyl-sn-glycero-3-phosphocholine (DOPC) liposomes were prepared from the most cytotoxic organic solvent extract and their cytotoxicity was also evaluated. All results collectively showed that hexane extract and its solid nanoparticles as well as its liposomal form exhibited high cytotoxic activity. DPPC/DOPC-hexane extract cytotoxicity selectively depends on the cell line and DOPC liposomal form was characterized by reduced $\mathrm{IC}_{50}$ compared with the other preparations/extracts, the average $\mathrm{IC}_{50}$ value is $165.8 \pm 3 \mu \mathrm{g} / \mathrm{ml}$. The antiproliferative activity of propolis was associated to multiple modes of actions including apoptosis and nitric oxide production and as indicated by the HPLC and FTIR results, it is functioning in many propolis ingredients rather than a single component and influenced by the presence of more lipophilic components within the extract and not by the extract mass yield. These results may have an impact on the multidrug resistivity issue.
\end{abstract}

Key words: Nanoparticles - Liposomes - Propolis - Cytotoxicity - Apoptosis - Cancer Nitric oxide

\section{Introduction}

According to the World Health Organization (WHO), in Africa, up to $80 \%$ of the population uses traditional medicine for primary health care while, in Europe, North America and other industrialized regions, over $50 \%$ of the populations have used complementary or alternative medicine at least once (WHO fact sheet $\mathrm{N}^{\circ} 134,2003$ ).

Propolis, a brownish resinous material, is a natural remedy that has been extensively used since ancient Egyptians to embalm cadavers. By the time, its medicinal properties

Correspondence to: Mahmoud Siddick Sherif, 2 Al-Ahram street, P.O. Box 90, Giza, Egypt

E-mail: sheri_sm@yahoo.com as an antiseptic and cicatrizant in wound treatment and as mouth disinfectant were recognized. Recently, it is recommended as anti-bacterial, anti-fungal, anti-viral, hepatoprotective and anti-inflammatory component, to increase the body's natural resistance to infections and to treat gastroduodenal ulcers. Nowadays, it is available as capsules and included in many industries as cosmetics and healthy food (Dimov et al. 1992; Serkedjieva et al. 1992; Remirez et al. 1997; Kimoto et al. 1998; Claus et al. 2000; Koo et al. 2000; Vynograd et al. 2000; Rossi et al. 2002; Gonzalez et al. 2006). It has an anti-neoplastic activity against many cancer cells and it is also able to inhibit cell division and protein synthesis (Sudlina et al. 1993; Piantelli et al. 1995; Shimizu et al. 1999; Galati et al. 2000; Reed 2000; Luo et al. 2001; Orsolic and Basic 2003; Aso et al. 2004; Chen et 
al. 2004; Kumazawa et al. 2004; Orsolic et al. 2004; Mouse et al. 2012).

This article screening the potential anti-cancer activity of propolis, taking into account the possible role of the employed solvent for the extraction, and focus on the most potent organic solvent extract where the nanoparticles were prepared. The mode of action underlying these positive effects was also considered.

\section{Materials and Methods}

\section{Materials}

Propolis was obtained from the ministry of agriculture production facility at Shoubra El Khema district (Cairo, Egypt) during April 2014. Four adherent cancer cell lines were utilized in this study, human ovarian adenocarcinoma SKOV3, Cervical cancer cells (Hela) and breast cancer (MCF-7) were purchased from the American Type Culture Collection (Rockville, MD, USA). SKOV3-TR, the taxol resistant variant of SKOV3, was a kind gift from Dr. Duan Zhenfeng (MGH, Boston, MA). Cell culture media and supplements were purchased from Cell-Gro (Kansas City, MO, USA). Hela, SKOV3 and SKOV3-TR cells were cultured in RPMI 1640 media while MCF-7 was cultured in MEM media. Both media were supplemented with $10 \%$ fetal bovine serum and $1 \%$ penicillin, streptomycin, and amphotericin. Cells were maintained at $37^{\circ} \mathrm{C}$ in a humidified incubator with $5 \% \mathrm{CO}_{2}$, and were passage according to ATCC protocols. CellTiterblue $^{\circledR}$ was purchased from Promega (Madison, WI). All buffer solution components were analytical grade and the organic solvents were HPLC grade. DPPC and DOPC were purchased from Avanti Polar lipids, authentic standards were obtained from Sigma (Sigma, Sigma, St. Louis, MO, USA).

\section{Methods}

\section{Propolis extracts}

Four propolis extracts were prepared by suspending $50 \mathrm{~g}$ of propolis powder in $100 \mathrm{ml}$ of: bi-distilled water (Water-EXT), hexane (Hexane-EXT), absolute ethanol (Ethanol-EXT) and $70 \%$ ethanol (Hydroalcohol-EXT) and let to stand for $24 \mathrm{~h}$ at $4^{\circ} \mathrm{C}$. Then, all preparations were filtered through Whatmann no. 1 filter paper followed by a successive filtration using sterilized microsyringe filters with diameters $0.8,0.45$ and $0.22 \mathrm{~mm}$ to remove any suspended materials. The resulting supernatants were subjected to dryness using freeze-drying (Water-EXT) and the rotary evaporator to remove the solvents from the rest of the extracts. Finally, the resulting dried materials were weighted and taken in a known volume with the corresponding solvents and kept in $4^{\circ} \mathrm{C}$ for analysis and further studies.

\section{Spectroscopic investigations}

The structure of the native four extracts was investigated by UV-Vis spectroscopy in the range 190-500 $\mathrm{nm}$ using thermo-fisher spectrometer where equal concentrations were used. On the other hand, Fourier transform infrared spectroscopy (FTIR) was recorded for all extracts using Nicolet is5 spectrometer (Thermo-fisher). The extracts were layered on $\mathrm{KBr}$ disks and freeze-dried for $30 \mathrm{~min}$. Then the vibrational characteristics were recorded in the range $4000-400 \mathrm{~cm}^{-1}$ with resolution $4 \mathrm{~cm}^{-1}$. The spectrometer was operated under continuous $\mathrm{N}_{2}$ purging to reduce the interference of atmospheric $\mathrm{CO}_{2}$ and humidity. All measurements were repeated in triplicate and their representative average spectrum was plotted using OriginPro software and shown in the results.

\section{HPLC separation}

HPLC analysis was done with Hitachi Elite LaChrome liquid chromatography equipped with Hitachi autosampler (L-2200) and Diode Array detector (DAD L-2455). Degassed and previously filtered solvent system consisted of Acetonitrile (solvent A) and water (solvent B) were employed for gradient separation which accomplished with reverse phase stainless steel column (RP C18, Waters) with dimensions $4.6 \times 250 \mathrm{~mm}$ and $5 \mathrm{~mm}$ particle size at a flow rate of $1 \mathrm{ml} / \mathrm{min}$ for $40 \mathrm{~min}$. The gradient was applied in a three steps each of them taking $10 \mathrm{~min}$. At the beginning, the gradient was solvent A (100\%), the second time interval, it was $50 \%$ of both solvents and at the end it was pure solvent (B).

\section{Preparation of solid nanoparticles}

Separately, aliquots from the three organic solvent extracts correspond to $5 \mathrm{mg}$ were transferred to a round bottom flask and the solvent was removed by the rotary evaporator until complete dryness. The resulting dried film was hydrated with $5 \mathrm{ml}$ de-ionized water, followed by ultrasonication using an ultrasonic probe for $3 \mathrm{~min}$ where the solution turned almost clear. The final volume was adjusted so that the final concentration of nanoparticles was $1 \mathrm{mg} / \mathrm{ml}$.

\section{Preparations of liposomes-loaded propolis extract}

Phospholipid liposomes were prepared using 1,2-dipalmitoyl-sn-glycero-3-phosphocholine (DPPC) or 1,2-dioleoylsn-glycero-3-phosphocholine (DOPC) by the film hydration method. Briefly, $5 \mathrm{mg}$ of phospholipids in chloroform was 
transferred to a round-bottom flask and $1 \mathrm{mg}$ of organic solvent extract was added. The mixture was sonicated for $0.5 \mathrm{~min}$ after that the solvent was removed by rotary evaporation under reduced pressure. After complete dryness, the dried film was hydrated with phosphate buffer saline $(\mathrm{pH}$ 7.2). The water bath temperature was adjusted to be just above the phase transition temperature of the selected phospholipid.

\section{Particle size distribution and zeta potential measurements}

The particle size was measured by the dynamic light scattering using ZetaPALS system (Brookhaven Instruments Corporation, Holtville, NY, USA) at $90^{\circ}$ light scattering and the temperature was maintained at $25^{\circ} \mathrm{C}$, in a disposable cell by diluting $50 \mu \mathrm{l}$ of nanopreparation to $5 \mathrm{ml}$ with de-ionized water. Surface charge of the nanopreparations was measured with the same Zeta PALS system in de-ionized water and was monitored for three months.

\section{Cell viability assays}

Cells were seeded in 96-multi-well plates at a density of $3000-5000$ cell/well, depending on the cell line for $24 \mathrm{~h}$ in serum complete media. The media were removed and cells were washed with $200 \mu \mathrm{l}$ serum complete media. After adding $200 \mu \mathrm{l}$ of the medium, the plant extract or nanopreparations were added $(100 \mu \mathrm{l})$ and the plates were continuously incubated for $48 \mathrm{~h}$. The culture medium was discarded and the remaining of the tested material was removed by thorough washing with fresh media. Cells were trypsinized, counted and the survival rate was determined by celltitre blue ${ }^{(\mathrm{R})}$ protocol according to the manufacture's procedure (Promega, Madison, WI). The fluorescence (excitation $530 \mathrm{~nm}$, emission $590 \mathrm{~nm}$ ) was measured using a Synergy HT multi-detection microplate reader (Biotek, Winooski, VT). The treatment was carried out in triplicate and at least 3 different assays.

\section{Apoptotic activity}

Apoptotic activity was determined by flow cytometry (BD FACSCalibur, BD BioSciences, CA, USA) and the apoptotic detection system; Annexin V-FTIC:PI (Sigma, St. Louis, MO, USA). The resulted data were acquired and analyzed by the provided software (BD FACSComp). The cells were seeded in 6-well plates with a density 200,000 cell/well and allowed to attach for $24 \mathrm{~h}$. After discarding the media, cells were supplied with fresh media and continuously treated with the half maximal inhibitory concentration $\left(\mathrm{IC}_{50}\right)$ of the tested materials as predetermined from the cytotoxicity measurement for $48 \mathrm{~h}$. At the end of the treatment, cells were detached by trypsin and centrifuged for $5 \mathrm{~min}$ at
$1400 \mathrm{rpm}$. Then, the medium was discarded and the cells washed twice with cold PBS. Annexin V-FTIC ( $5 \mu \mathrm{l} /$ well) and PI $(10 \mu \mathrm{l} /$ well $)$ were added and incubated for $10 \mathrm{~min}$ at room temperature.

\section{Nitric oxide}

Intracellular nitric oxide was measured in living cells under physiological conditions by nitric oxide synthase kit (Sigma, St. Louis, MO, USA). The detection system utilizes a cellpermeable diacetate derivative of 4,5-diaminofluorescein (DAF-2 DA). DAF-2 DA penetrates cells rapidly, where it is hydrolyzed by intracellular esterase activity to DAF-2 that, in turn, reacts with NO produced by nitric synthase to form a fluorescent triazolofluorescein. The resulted fluorescence (excitation: $490 \mathrm{~nm}$ and emission: $520 \mathrm{~nm}$ ) was detected by the plate reader (Kojima et al. 1998; Navarro-Antolin and Lamas 2001). The cells were seeded in black bottom 96-well plates at a density of 50,000 cell/well and allowed to attach for $24 \mathrm{~h}$. After treatment with the $\mathrm{IC}_{50}$ of the tested materials for $48 \mathrm{~h}$, nitric oxide was detected according to the manufacture's procedure.

\section{Data analysis}

Experiments are reported as mean \pm SD and were generated in multiples of triplicate for proper statistical evaluation. Comparisons between two groups were made using Student's $t$-test and the significance level was determined by a $p$-value $<0.05$. Spectral analysis was carried out with OriginPro software (Origin 2015, OriginLabcorporation, MA, USA).

\section{Results}

\section{Extraction yield}

The extraction yield (mass of extract/mass of dried material) percentage indicates that absolute ethanol was associated with the highest yield percentage $(35.7 \%)$ followed by the hydroalcohol solvent (23.7\%). For hexane extract it was 5.1\% and for water extract it was $3 \%$.

\section{Characterization of propolis extracts}

\section{UV spectra}

The UV-VIS spectra of all propolis extracts (Figure 1) showed strong absorption in the range 270-290 $\mathrm{nm}$. Water extract showed one peak at $278 \mathrm{~nm}$ suggesting one principal compound or group of closely related compounds. Both 


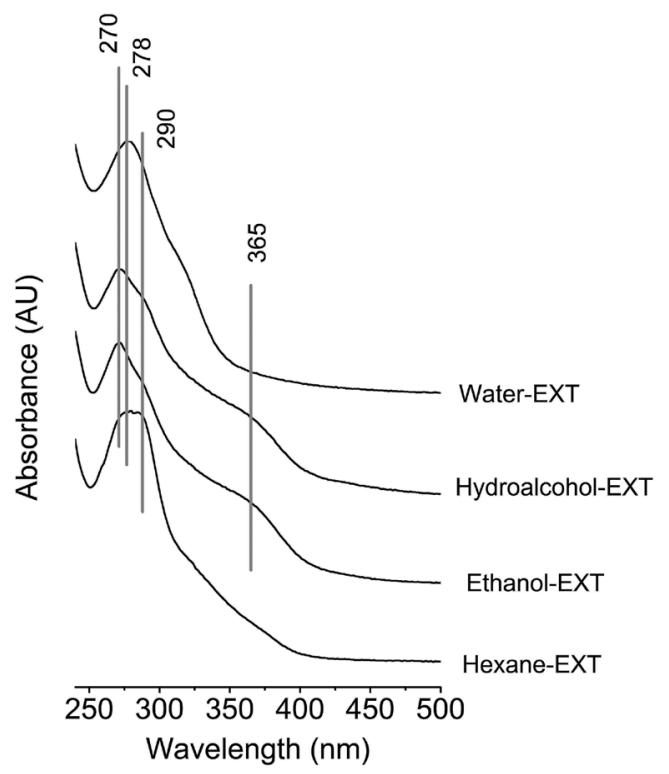

Figure 1. Characteristic UV-VIS spectra of propolis extracts.

hydroalcohol (70\% ethanol) and ethanol extracts were characterized by two absorption peaks at 270, 290 and shoulder at $365 \mathrm{~nm}$, reflecting the possibility of three compounds/ groups. On the other hand, hexane extract showed a broad absorption peak that covers the range $270-290 \mathrm{~nm}$.

\section{Infrared spectroscopy}

The characteristic infrared spectra of dried-water based extract and the other three solvent extracts -hydroalcoholic

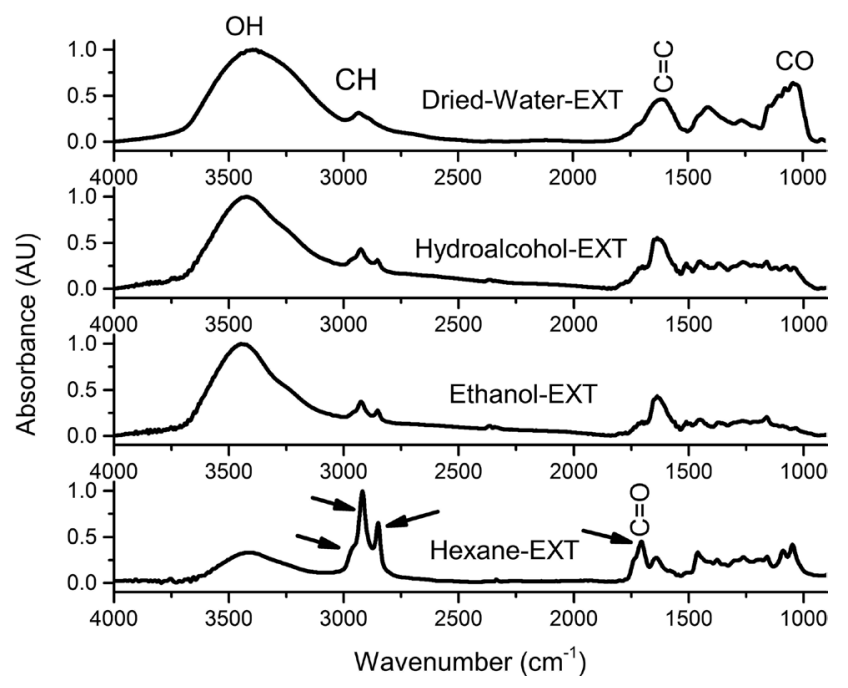

Figure 2. Typical FTIR spectra of propolis extracts.

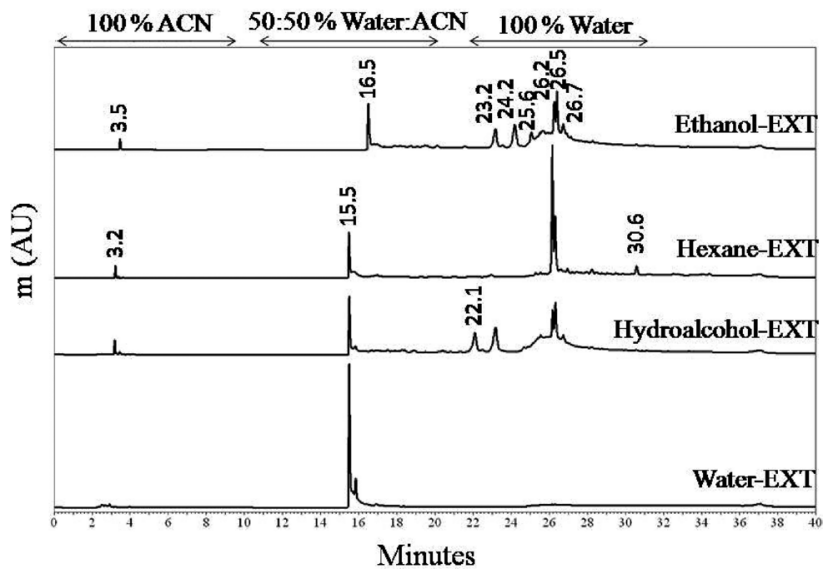

Figure 3. HPLC chromatographic elution pattern of different propolis extracts.

(70 \% ethanol), ethanol and hexane - are given in Figure 2. The hexane extract shows a remarkable structural differences relative to the other three extracts with reduced absorption intensity in the hydroxyl peak $\left(4000-3000 \mathrm{~cm}^{-1}\right)$, increased absorption intensity in the stretching vibration of methyl and methylene $\mathrm{CH}\left(3000-2800 \mathrm{~cm}^{-1}\right)$ and in the absorption peak that detected around $1710 \mathrm{~cm}^{-1}$ (carbonyl bond). These absorption characteristics are typical for lipophilic components.

\section{HPLC results}

Figure 3 shows the gradient-chromatographic profile for all propolis extracts at $280 \mathrm{~nm}$. The number of the major fractions observed in the separating profiles was $8,7,5$ and 2 for ethanol, hydroalcohol, hexane and water extracts, respectively. The HPLC chromatograms also indicated that hexane extract is characterized by the strong peak height for the separated component with retention time $\left(r_{t}\right)$ of 26.2 and $26.5 \mathrm{~min}$ as well as detectable component at $r_{t}$ of $30.6 \mathrm{~min}$. For the ethanol and hydroalcohol extracts, the same separating pattern could be noticed except for those components with $r_{t}$ of 16.5, 22.1, 24.2 and $25.1 \mathrm{~min}$. On the other hand, water extract showed only two components/groups with $r_{t}$ of 15.5 and $15.8 \mathrm{~min}$. The elution pattern of the authentic standards (Figure 4) showed that gallic acid eluted in the ACN phase (0-10 min), while the rest of the standards were observed in the $50 \%$ mobile phase (11-21 min) and, none of the standards were eluted in the water phase (22-32 $\mathrm{min})$.

\section{Particle size and zeta potential measurements}

The mean particle size obtained for the solid nanoparticles (NP) was $296.5 \pm 2.7,195.9 \pm 3.2$ and $244.6 \pm 4.6 \mathrm{~nm}$ cor- 


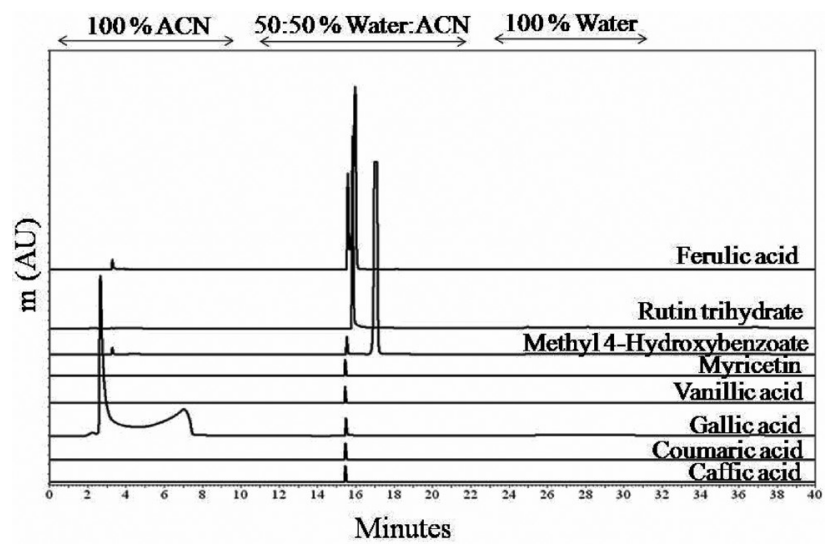

Figure 4. HPLC display of chromatographic elution pattern for phenolic standards.

responding to hydroalcohol-EXT-NP, hexane-EXT-NP and ethanol-EXT-NP. The liposomal forms of either DPPC or DOPC that containing hexane extract was characterized by a significantly reduced particle size compared to the NP forms; the mean particle size of the DPPC-hexane-EXT liposomes was $125.6 \pm 1.0 \mathrm{~nm}$ while that of DOPC-hexaneEXT was $98 \pm 1.8 \mathrm{~nm}$. On the other hand and during the three months follow up period, a large negative zeta potential was found for all nanopreparations with a magnitude of $-44 \pm 2.8,-55 \pm 3.7,-40 \pm 6.2,-26 \pm 4.2$ and $-20 \pm 2.9 \mathrm{mv}$ that corresponds to ethanol-EXT-NP, hexane-EXT-NP,
hydroalcohol-EXT-NP, DPPC-hexane-EXT and DOPChexane-EXT, respectively.

\section{Cytotoxicity of propolis extracts and nanopreparations}

The screening results of the cytotoxic activity of all propolis extracts are shown in Figures 5 and 6. All extracts were characterized by a remarkable cytotxicity in all cell lines. The cytotoxic activity of hexane extract was strongest with $\mathrm{IC}_{50}$ of $232.7 \pm 3.7,176.7 \pm 2.9,184.7 \pm 3.8$ and $197.1 \pm$ $4.6 \mu \mathrm{g} / \mathrm{ml}$ for MCF-7, Hela cells, SKOV3-sens and SKOV3$\mathrm{TR}$, respectively. Hela cells are the most sensitive cell line for hexane and hydroalcohol extracts with initial effective concentration of $1.3 \pm 1.0 \mu \mathrm{g} / \mathrm{ml}$.

The cytotoxic activity of solid nanoparticles (NP) prepared from organic solvents-containing extracts (Figures 5 and 6) indicate that all cell lines were sensitive to these nanoparticles (but Hela cells for ethanol-EXT-NP), with the hexane NP most effective. The $\mathrm{IC}_{50}$ for hexane-EXT-NP is $222.4 \pm 2.3,215.7 \pm 7.3,181.2 \pm 3.9$ and $140.5 \pm 5.5 \mu \mathrm{g} /$ $\mathrm{ml}$ corresponds to MCF-7, Hela cells, SKOV3 sensitive and drug-resistive, respectively. On the other hand, DPPC and DOPC liposomes containing hexane extracts were characterized by fluctuated cytotoxicity that depends on the cell line. Hela cells are not sensitive to both liposomal forms. MCF-7 showed some positive results against both liposomal forms with first effective concentration of $333.3 \mu \mathrm{g} / \mathrm{ml}$. The other two cell lines (SkOV3 sensitive and resistive) were greatly
MCF-7
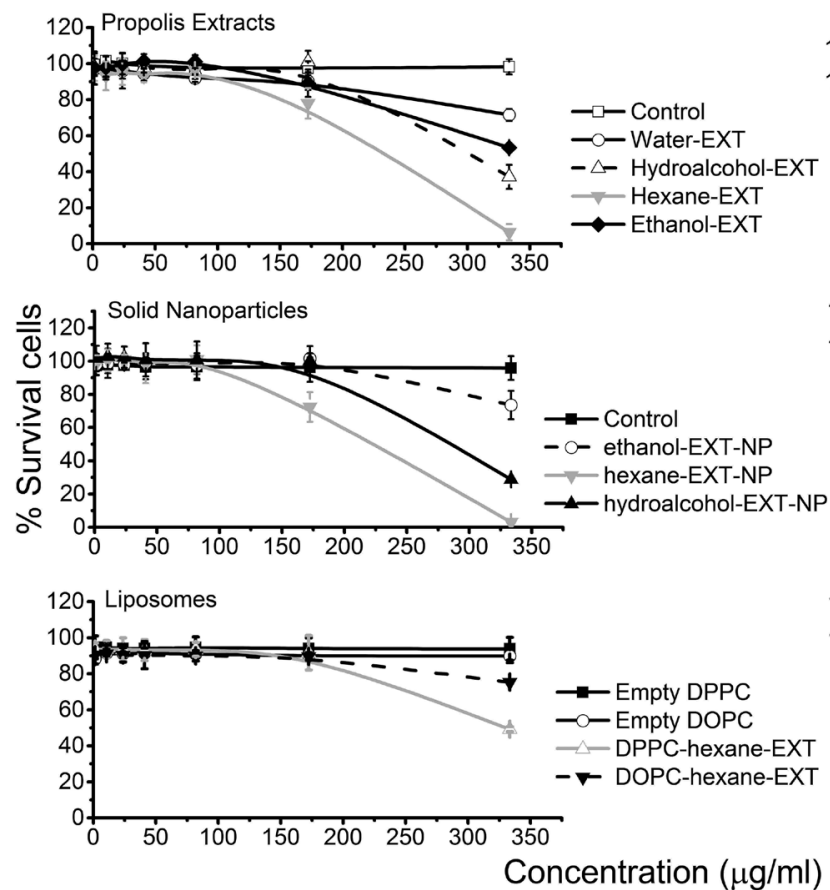

Hela
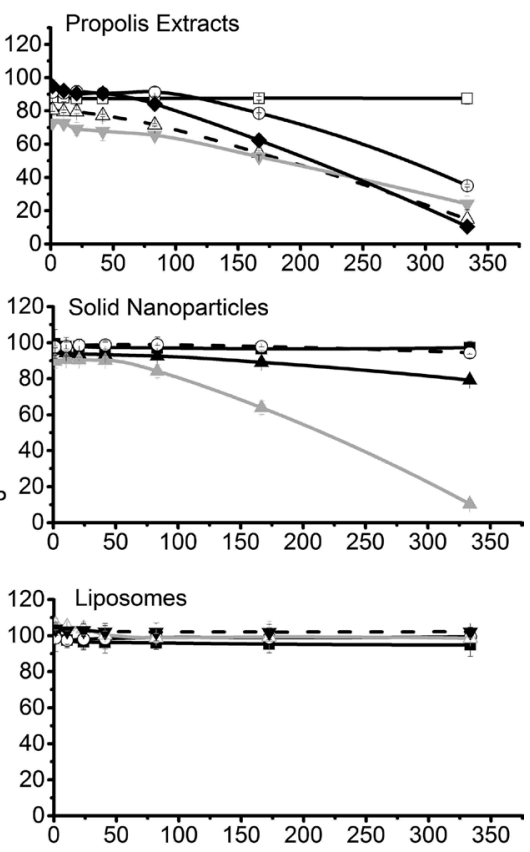

Figure 5. Cytotoxicity of different propolis extracts, solid nanoparticles and liposomal forms of hexane-EXT in MCF-7 and Hela cells. 
SKOV3-sens
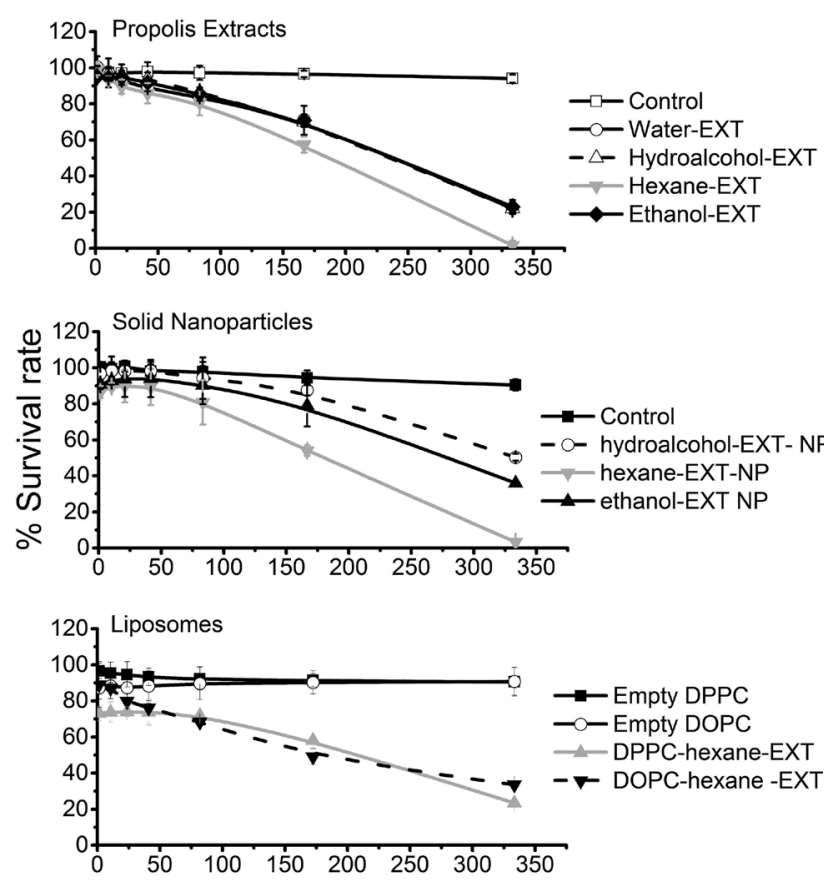

Concentration $(\mu \mathrm{g} / \mathrm{ml})$
SKOV3 - TR
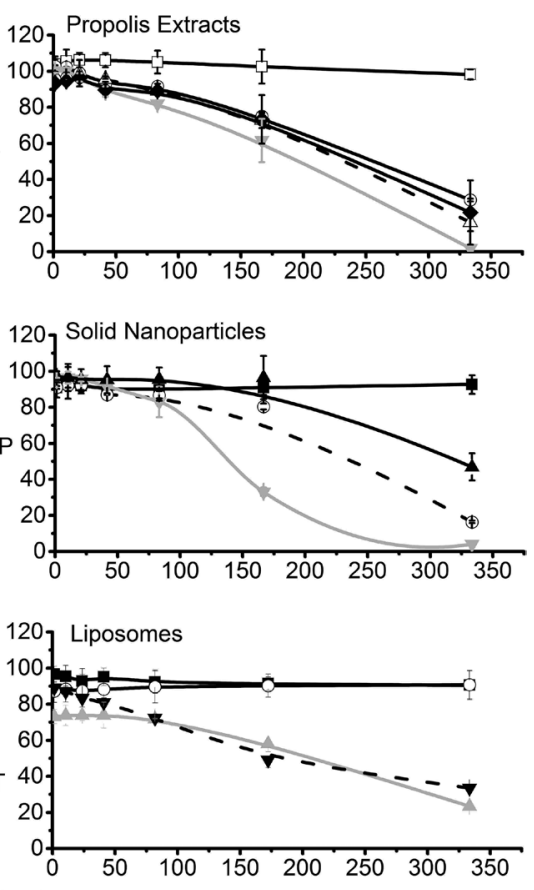

Figure 6. Cytotoxicity of different propolis extracts, solid nanoparticles and liposomal forms of hexane-EXT in SKOV3 cells and its taxol resistive variant (SKOV3-TR). affected with an average $\mathrm{IC}_{50}$ of $224.7 \mu \mathrm{g} / \mathrm{ml}$ for DPPChexane-EXT and $166.7 \mu \mathrm{g} / \mathrm{ml}$ for DOPC-hexane-EXT and, first effective concentration of $1.3 \mu \mathrm{g} / \mathrm{ml}$ for both liposomal forms. Table 1 summarizes the IC $_{50}$ for all extracts and nanopreparations.

\section{Apoptotic activity of Propolis extracts and nanoparticles}

After treatment with the $\mathrm{IC}_{50}$ of different hexane extract/ preparations for $48 \mathrm{~h}$, their apoptotic activities were determined by the annexinV-PI Apoptosis Kit (Figure 7). The lower left quadrant (LL) represents the viable cells (live cells, Annexin-PI-), the lower right quadrant (LR) shows the early apoptotic cells (Annexin+PI-). The upper right quadrant (UR) reflects the percentage of dead cells (late apoptosis/ necrotic cells, Annexin+PI+) while, the upper left one (UL) indicates necrotic cells (annexin-PI+). The results showed that the percentage of dead cells (UR) is higher in SKOV3 sensitive and drug-resistive cells when treated by all hexane preparations; this was associated with an obvious increase in the percentage of necrotic cells (UL) as a result of DPPChexane-EXT treatment. Comparing the apoptotic activity

Table 1. The $\mathrm{IC}_{50}(\mu \mathrm{g} / \mathrm{ml})$ for propolis extracts and nanopreparations as determined in different cancer cell lines and the particle size of nanopreparations

\begin{tabular}{lcccrc}
\hline & MCF-7 & Hela cells & SKOV3-sens & SKOV3-TR & Particle size $(\mathrm{nm})$ \\
\hline Water-EXT & N.A & $283.2 \pm 3.8$ & $235.8 \pm 6.4$ & $257 \pm 5.9$ & - \\
Hydroalcohol-EXT & $302 \pm 6.8$ & $185.4 \pm 2.6$ & $235.6 \pm 4.9$ & $233.1 \pm 7.8$ & - \\
Hexane-EXT & $232.7 \pm 3.7$ & $176.7 \pm 2.9$ & $184.7 \pm 3.8$ & $197.1 \pm 4.6$ & - \\
Ethanol-EXT & $330.5 \pm 5.1$ & $209.3 \pm 4.6$ & $235.9 \pm 6.6$ & $241.8 \pm 4.7$ & - \\
hydroalcohol-EXT-NP & $285.4 \pm 6.9$ & N.A & $333.9 \pm 9.4$ & $244 \pm 7.2$ & $296.5 \pm 2.7$ \\
hexane-EXT-NP & $222.4 \pm 2.3$ & $215.7 \pm 7.3$ & $181.2 \pm 3.9$ & $140.5 \pm 5.5$ & $195.9 \pm 3.2$ \\
ethanol-EXT-NP & N.A & N.A & $280.3 \pm 4.8$ & $322.2 \pm 7.9$ & $244.6 \pm 4.6$ \\
DPPC-hexane-EXT & $333.3 \pm 6.1$ & N.A & $170.1 \pm 3.3$ & $170.8 \pm 6$ & $125.6 \pm 2.0$ \\
DOPC-hexane-EXT & N.E & N.E & $167.9 \pm 4.8$ & $165.7 \pm 5.3$ & $98 \pm 1.8$ \\
\hline
\end{tabular}

N.A., not achieved; N.E., non-effective preparation. 

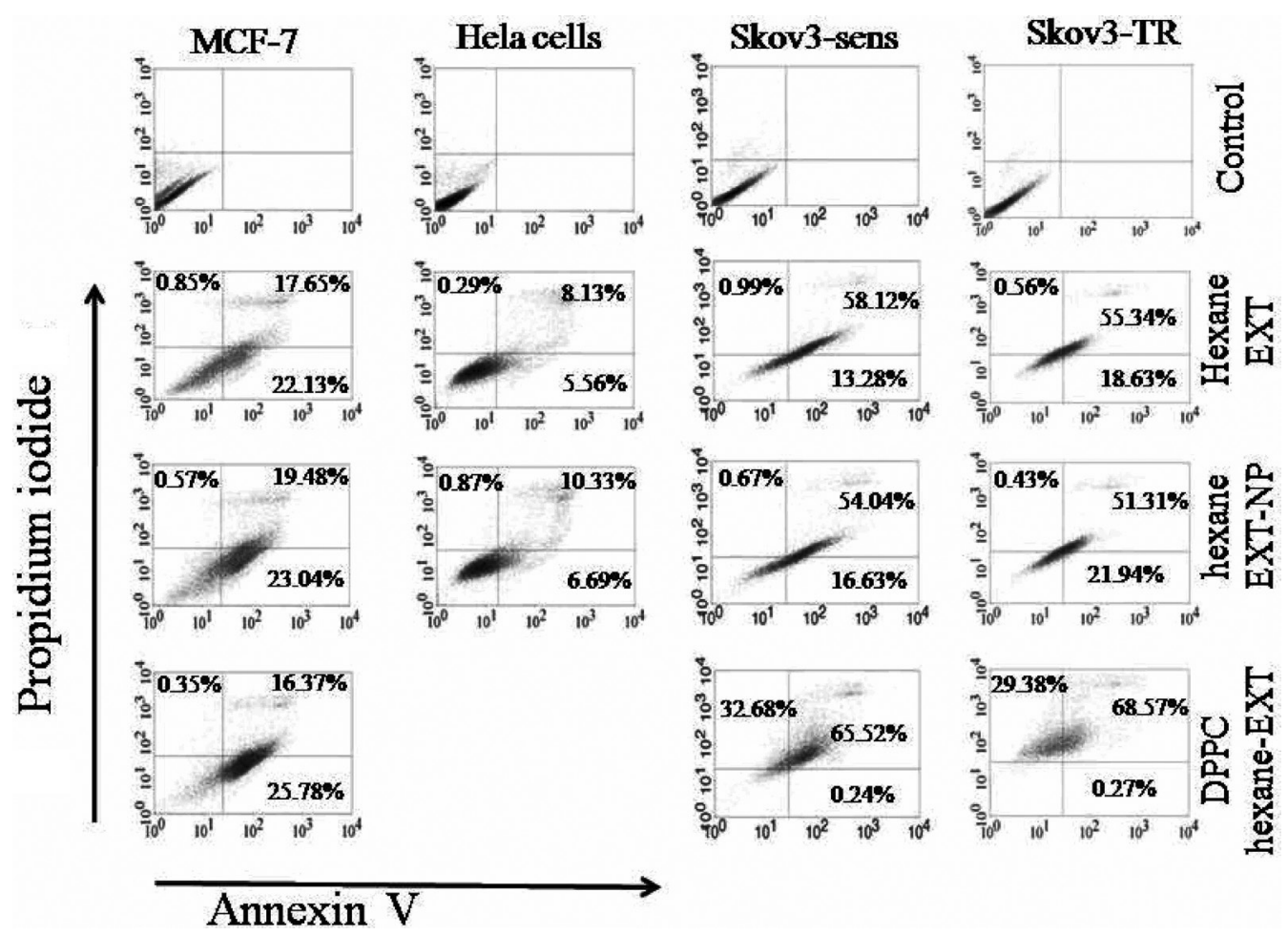

Figure 7. Annexin V-PI apoptotic activity of hexane-EXT and its nanopreparations displayed for all cancer cell monolayers.

of the four cell lines, Hela cells showed less percentage. This apoptotic activity can be ordered as SKOV3 (sensitive and drug resistive) $>\mathrm{MCF}-7>$ Hela cells. Interestingly, the DPPC liposomal form of the hexane extract does not show any apoptotic activity in Hela cells. Table 2 summarizes the details of the quadrants for all cancer cell lines.

\section{Nitric Oxide (NO)}

NO is a key player in several biological processes. The nitric oxide detection system enables the detection of produced nitric oxide (NO) in living cells under physiological conditions via nitric oxide synthase activity (iNOS). The histograms in Figure 8 show the increase in NO production in all included cancer cell lines expressed as percentage increase relative to the corresponding control cells. Exposing the MCF-7 cells to hexane extract/nanopreparations was associated with the highest production level of NO in particular the hexane solid nanoparticles. The production of $\mathrm{NO}$ as a function of the included cell lines can be ordered as MCF-7 > SKOV3-TR $>$ SKOV3-sens $>$ Hela cells.

\section{Discussion}

Systemic administration of chemotherapeutic drugs and/or radiotherapy affects both cancerous cells as well as healthy ones. Therefore, plants still represent an important source in the development of drugs that are characterized by effective anti-cancer activity, non-expensive and undesirable side effects.

The UV-spectra of phenolic compounds and flavonoids typically lie in the range $230-290 \mathrm{~nm}$ and corresponds to $\pi-\pi^{*}$ electrons in the benzene ring. The shoulder observed at $365 \mathrm{~nm}$ corresponds to the transfer of $\pi-\pi^{*}$ electrons in the secondary aromatic ring (B-ring) and chroman ring

Table 2. Apoptotic activity percentages of hexane extract and its nanopreparations in different cancer cell monolayers.

\begin{tabular}{|l|ccc|ccc|ccc|ccc|}
\hline & \multicolumn{3}{|c|}{ MCF-7 } & \multicolumn{3}{c|}{ Hela cell } & \multicolumn{3}{c|}{ SKOV3-sens } & \multicolumn{4}{c|}{ SKOV3-TR } \\
\cline { 2 - 14 } & Apoptotic & Dead & Necrotic & Apoptotic & Dead & Necrotic & Apoptotic & Dead & Necrotic & Apoptotic & Dead & Necrotic \\
\hline Hexane-EXT & 22.13 & 17.65 & 0.85 & 5.56 & 8.13 & 0.29 & 13.28 & 58.12 & 0.99 & 18.63 & 55.34 & 0.56 \\
Hexane-EXT-NP & 23.04 & 19.48 & 0.57 & 6.69 & 10.34 & 0.87 & 16.63 & 54.04 & 0.67 & 21.94 & 51.31 & 0.43 \\
DPPC-Hexane-EXT & 25.78 & 16.37 & 0.35 & \multicolumn{3}{c|}{ Not effective } & 0.24 & 65.52 & 32.68 & 0.27 & 68.57 & 29.38 \\
\hline
\end{tabular}




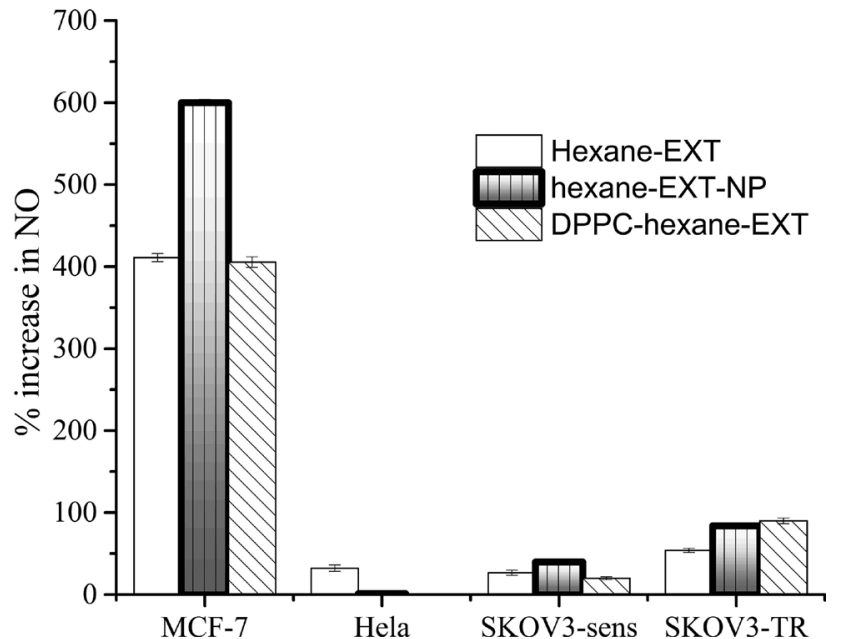

Figure 8. Percentage increase in nitric oxide production resulted from exposing cancer cell monolayers to the $\mathrm{IC}_{50}$ of hexane-EXT/ nanopreparations.

(C-ring) of polyphenolic compounds (Sisa et al. 2010; Masek et al. 2014). Based on these spectral characteristics, Water-EXT ( $\lambda_{\max } 280 \mathrm{~nm}$ ) mainly contains benzoyl system (Sisa et al. 2010). Hexane-EXT showed broad UV band $(270-290 \mathrm{~nm})$ that reflect all the previously mentioned structural characteristics in addition to the keto-hydroxyl tautomerism compound (Masek et al. 2014).

The FTIR spectroscopic investigation revealed different band characteristics that were associated to various functional compounds in the extracts. For the Water-EXT, hydroxyl band $(\mathrm{OH})$ indicates the presence of phenols and alcohols. The presence of the broad C-O band around 1045 $\mathrm{cm}^{-1}$ reflects the presence of alcohols, carboxylic acids, esters and ethers (Liu et al. 2006; Deepa et al. 2014). Accordingly, the Water-EXT is characterized by the presence of higher phenols/carbohydrates content as compared with the other organic extracts. On the other hand, the hydroalcohol-EXT and Ethanol-EXT showed more phenolic compounds. The Hexane-EXT characteristic spectrum indicates higher lipophillic compounds. On the other hand, the HPLC chromatogram (Figure 4) clearly reflect the chemical composition complexity of propolis, and the simplest chromatogram was that of Water-EXT. Interestingly, the unidentified bands that have $r_{t}$ between 22 and 32 min can be directly associated with the antitumor activity in particular those for HexaneEXT ( $r_{t}: 26.2,26.5$ and $\left.30.6 \mathrm{~min}\right)$. These constituents may be due to phenolic derivatives. The spectrophotometric results together with the HPLC chromatograms clearly showed that the antitumor activity of propolis extracts is functioning in many propolis constituents rather than a single component as previously mentioned by Serkedjieva et al. (1992) and

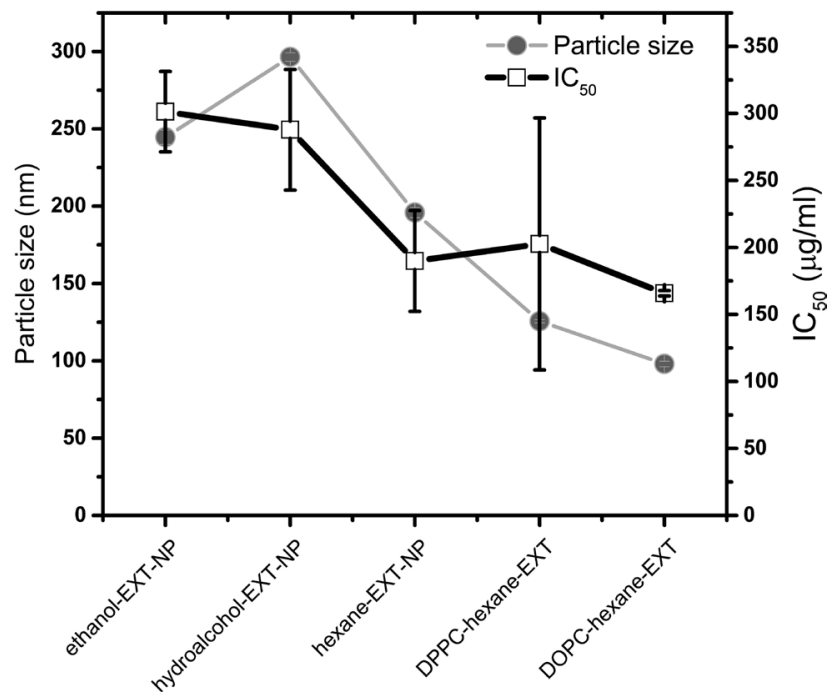

Figure 9. The impact of particle size variation on the $\mathrm{IC}_{50}$ of propolis nanopreparations.

Rossi et al. (2002), and that the lipophilic constituents has an influential and effective role in the ability to kill cancer cells.

All extracts exerts significant cytotoxicity, this cytotoxicity was greatly enhanced with the solid nanoparticles in particular the hexane one and it was found to be dose-dependent and not cell-specific. Although the DOPC liposomal form of the hexane extracts turned to be the potentially effective preparation in inhibiting and killing the cancer cells, the cytotoxicity of both DPPC and DOPC-hexane-EXT was cell specific, and the structural differences of both phospholipids and accordingly in their physical characteristics did not affect this activity. On the other hand, SKOV3 (sensitive and drug resistive) cells were sensitive to all propolis preparations and the liposomal forms treatment was associated with the lowest and statistically significant $\mathrm{IC}_{50}$.

$\mathrm{NO}$, a free radical and signaling molecule, in one hand is involved in many normal cell physiological functions and in the other hand, it is implicated in the etiology and prognosis of many diseases that include cancers and metastasis which are responsible for a high cancer mortality deaths. It is known that it can inhibit cell proliferation and induces apoptosis in high concentrations. Increased NO production has been reported in breast cancer cells treated with various apoptotic agents and peptide hormones (Bani et al. 1995; Reveneauet al. 1999; Tschugguel et al. 1999). Our results indicate that the higher rate of NO production (Figure 8) was detected in the breast cancer cell line MCF-7. For the ovarian cancer cell lines (SKOV3) this rate was reduced while in the Hela cells it was the least. Regarding the apoptotic activity of propolis which contradicts these findings, it is clear that propolis apototic activity is NO-independent and propolis hexane 
extract and its nanopreparations might have enhancing effects on iNOS gene which may lead to enhancing production of NO. The production of NO due to propolis preparations treatment obviously depends on the cancer phenotype.

Nanoscale particles are used to increase the cellular uptake and hence enhance the cellular cytotoxicity. The interplay between the variation in particle size of the involved nanopreparations and the cellular cytotoxicity in all cancer cell lines (Figure 9) was not followed by improvement in the $\mathrm{IC}_{50}$. It is well known that zeta potential has been used to characterize the stability of the colloidal drug delivery systems; as the magnitude of the zeta potential increases, repulsion between particles will be greater and leading to more stable preparation (Chibowski and Szczes 2016). It is clear from the zeta potential measurements that all nanopreparations involved in this study are stable. During the three months follow up period, the observed differences in the measured zeta potential between propolis extract nanoparticles, in particularly hexane-EXT-NP, and its liposomal forms turn the NP to be more recommended.

\section{Conclusion}

Hexane-EXT-NP was found to be effective against all cancer cell lines included in the study and has an average $\mathrm{IC}_{50}$ of $189.9 \pm 37.6 \mu \mathrm{g} / \mathrm{ml}$, and its cytotoxicity is superior compared with its liposomal forms. All results collectively suggest that propolis extracts/nanoparticles kill cancer cells by a process that involves apoptosis and nitric oxide production, and mass necrosis was associated to DPPC-hexane-EXT in both SKOV3 cell lines. This multimode of action may have an impact on the drug-resistivity problem and a propolis lifestyle diet is recommended.

Acknowledgements. Sherif S.M. was financially supported by Cairo Initiative Program.

Conflict of interest. No conflict of interest.

\section{References}

Aso K, Kanno S, Tadano T, Satoh S, Ishikawa M (2004): Inhibitory effect of propolis on the growth of human leukemic U937. Biol. Pharm. Bull. 27, 727-730 https://doi.org/10.1248/bpb.27.727

Bani D, Masini E, Bello MG, Bigazzi M, Sacchi TB (1995): Relaxin activates the L-arginine-nitric oxide pathway in human breast cancer cells. Cancer Res. 55, 5272-5275

Chen CN, Wu CL, Lin JK (2004): Propolin C from propolis induces apoptosis through activating caspases, Bid and cytochrome $\mathrm{C}$ release in human melanoma cells. Biochem. Pharmacol. 67, 53-66

https://doi.org/10.1016/j.bcp.2003.07.020
Chibowski E, Szczes A (2016): Zeta potential and surface charge of DPPC and DOPC liposomes in the presence of PLC enzyme. Adsorption 22, 755-765 https://doi.org/10.1007/s10450-016-9767-Z

Claus R, Kinscherf C, Bonaterra G, Basnet P, Metz J, Deigner HP (2000): Antiapoptotic effects of propolis extract and propol on human macrophages exposed to minimally modified low density lipoprotein. Arzneim Forsch/Drug Res. 50, 373-379

Deepa S, Sripriya N, Bangaru C (2014): Studies on the phytochemistry, specroscopic and antibacterial efficacy of Salicornia Brachiata. Int. J. Pharm. Pharmaceut. Sci. 6, 430-432

Dimov V, Ivanovska N, Bankova V, Popov S (1992): Immunomodulatory action of propolis: IV. Prophylactic activity against gramnegative infections and adjuvant effect of the water-soluble derivative. Vaccine 10, 817-823 https://doi.org/10.1016/0264-410X(92)90043-J

Galati G, Teng S, Moridani MY, Chan TS, O‘Brien PJ (2000): Cancer chemoprevention and apoptosis mechanisms induced by dietary polyphenolics. Drug Metabol. Drug Interact. 17, 311-349 https://doi.org/10.1515/DMDI.2000.17.1-4.311

Gonzalez R, Corcho I, Remirez D, Rodriguez S, Ancheta O, Merino N, González A, Pascual C (2006): Hepatoprotective effects of propolis extract on carbon tetrachloride-induced liver injury in rats. Phytother. Res. 9, 114-117 https://doi.org/10.1002/ptr.2650090207

Kimoto T, Arai S, Kohguchi M, Aga M, Nomura Y, Micallef MJ, Kurimoto M, Mito K (1998): Apoptosis and suppression of tumor growth by artepillin C extracted from Brazilian propolis. Cancer Detect. Prev. 22, 506-515 https://doi.org/10.1046/j.1525-1500.1998.00020.x

Kojima H, Sakurai K, Kikuchi K, Kawahara S, Kirino Y, Nagoshi H, Hirata Y, Nagano T (1998): Development of a fluorescent indicator for nitric oxide based on the fluorescein chromophore. Chem. Pharm. Bull. 46, 373-375 https://doi.org/10.1248/cpb.46.373

Koo H, Gomes BP, Rosalen PL, Ambrosano GM, Park YK, Cury JA (2000):In vitro antimicrobial activity of propolis and Arnica montana against oral pathogens. Arch. Oral Biol. 45, 141-148 https://doi.org/10.1016/S0003-9969(99)00117-X

Kumazawa S, Hamasaka T, Nakayama T (2004): Antioxidant activity of propolis of various geographic origins. Food Chem. 84, 329-339 https://doi.org/10.1016/S0308-8146(03)00216-4

Liu HX, Sun SQ, Lv GH, Chan KK (2006): Study on Angelica and its different extracts by Fourier transform infrared spectroscopy and two-dimensional correlation IR spectroscopy. Spectrochimica Acta, A: Molecular and Biomolecular Spectroscopy 64, 321-326 https://doi.org/10.1016/j.saa.2005.07.026

Luo J, Soh JW, Xing WQ, Mao Y, Matsuno T, Weinstein IB (2001): A benzo-gamma-pyran derivative isolated from propolis inhibits growth of MCF-7 human breast cancer cells. Anticancer Res. 21, 1665-1671

Masek A, Chrzescijanska E, Kosmalska A, Zabborski M (2014): Characteristics of compounds in hops using cyclic voltammetry, UV-VIS, FTIR and GC-MS analysis. Food Chem. 156, 353-361 https://doi.org/10.1016/j.foodchem.2014.02.005 
Mouse HA, Tilaoui M, Jaafari A, M'barek LA, Aboufatima R, Chait A, Abdelmajid Z (2012): Evaluation of the in vitro and in vivo anticancer properties of Moroccan propolis extracts. Rev. Bras. Farmacogn. 22, 558-567 https://doi.org/10.1590/S0102-695X2012005000030

Navarro-Antolin J, Lamas S (2001): Nitrosative stress by cyclosporin $\mathrm{A}$ in the endothelium: studies with the NO-sensitive probe diaminofluorescein-2/diacetate using flow cytometry. Nephrol. Dial. Transplant. 16, 6-9 https://doi.org/10.1093/ndt/16.suppl_1.6

Orsolic N, Basic I (2003): Immunomodulation by water-soluble derivative of propolis: a factor of antitumor reactivity. J. Ethnopharmacol. 84, 265-273 https://doi.org/10.1016/S0378-8741(02)00329-X

Orsolic N, Knezevic AH, Sver L, Terzic S, Basic I (2004): Immunomodulatory and antimetastatic action of propolis and related polyphenolic compounds. J. Ethnopharmacol. 94, 307-315 https://doi.org/10.1016/j.jep.2004.06.006

Piantelli M, Maggiano N, Ricci R, Larocca LM, Cappelli A, Scambia G, Isola G, Natali PG, Ranelletti FO (1995): Tamoxifen and quercetin interact with type II estrogen binding sites and inhibit the growth of human melanoma cells. J. Invest. Dermatol. 105, $248-253$ https://doi.org/10.1111/1523-1747.ep12317599

Reed JC (2000): Mechanism of apoptosis. Am. J. Pathol. 157, $1415-1430$ https://doi.org/10.1016/S0002-9440(10)64779-7

Remirez D, Gonzalez R, Rodriguez S, Ancheta O, Bracho JC, Rosado A, Rojas E, Ramos ME (1997): Protective effects of Propolis extract on allyl alcohol-induced liver injury in mice. Phytomedicine 4, 309-314 https://doi.org/10.1016/S0944-7113(97)80038-4

Reveneau S, Arnould L, Jolimoy G, Hilpert S, Lejeune P, SaintGiorgio V, Belichard C, Jeannin JF (1999): Nitric oxide synthase in human breast cancer is associated with tumor grade, proliferation rate, and expression of progesterone receptors. Lab. Invest. 79, 1215-1225

Rossi A, Longo R, Russo A, Borrelli F, Sautebin L (2002):The role of the phenethyl ester of caffeic acid (CAPE) in the inhibition of rat lung cyclooxygenase activity by propolis. Fitoterapia 73, S30-S37 https://doi.org/10.1016/S0367-326X(02)00188-0

Serkedjieva J, Manolova N, Bankova V (1992): Anti-influenza virus effect of some propolis constituents and their analogues (esters of substituted cinnamic acids). J. Nat. Prod. 5, 294-302 https://doi.org/10.1021/np50081a003

Shimizu S, Narita M, Tsujimoto Y (1999): Bcl-2 family proteins regulate the release of apoptogenic cytochrome $\mathrm{C}$ by the mitochondrial channel VDAC. Nature 399, 483-487 https://doi.org/10.1038/20959

Sisa M, Bonnet ML, Ferreira D, Van der Westhuizen JH (2010): Photochemistry of flavonoids. Molecules 15, 5196-5245 https://doi.org/10.3390/molecules 15085196

Sudlina GF, Mirzoeva OK, Pushkareva MA, Korshunova GA, Sumbatyan NV, Varfolomeev SD (1993): Caffeic acid phenethyl ester as a lipoxygenase inhibitor with antioxidant properties. FEBS Lett. 329, 21-24 https://doi.org/10.1016/0014-5793(93)80184-V

Tschugguel W, Schneeberger C, Unfried G, Czerwenka K, Weninger W, Mildner M. (1999): Expression of inducible nitric oxide synthase in human breast cancer depends on tumor grade. Breast Cancer Res. Treat. 56, 145-151 https://doi.org/10.1023/A:1006288526311

Vynograd N, Vynograd I, Sosnowski Z (2000): A comparative multicentre study of the efficacy of propolis acyclovir and placebo in the treatment of genital herpes (HSV). Phytomedicine 7, 1-6 https://doi.org/10.1016/S0944-7113(00)80014-8

Received: December 7, 2016

Final version accepted: June 18, 2017 